Journal of Advanced Research in Applied Sciences and Engineering Technology

\title{
Mixing Chamber for Preparation of Nanorefrigerant
}

\author{
Nur Fazlin Che Halim ${ }^{1,}$, Nor Azwadi bin Che Sidik ${ }^{1}$ \\ 1 Malaysia - Japan International Institute of Technology, Universit Teknologi Malaysia, Jalan Sultan Yahya Petra, 54100 Kuala Lumpur, Malaysia
}

\begin{tabular}{|c|c|}
\hline ARTICLE INFO & ABSTRACT \\
\hline $\begin{array}{l}\text { Article history: } \\
\text { Received } 24 \text { July } 2020 \\
\text { Received in revised form } 3 \text { September } 2020 \\
\text { Accepted } 21 \text { October } 2020 \\
\text { Available online } 14 \text { November } 2020\end{array}$ & $\begin{array}{l}\text { The last decade has seen the rapid advancement of nanofluid in several ways. } \\
\text { Nanofluid based on the refrigerant have been introduced as nanorefrigerant in recent } \\
\text { years due to their significant effects on the efficiency of heat transfer. Previous studies } \\
\text { showed some limitation in ways of dispersing nanoparticles into refrigerant. Hence, a } \\
\text { new idea of adding nanoparticles into refrigerant has been presented. A mixing } \\
\text { chamber has been designed to mix nanoparticles into high pressure refrigerant. The } \\
\text { mixing chamber design is drawn with five different wall thickness which are } 2 \mathrm{~mm}, 4 \\
\mathrm{~mm}, 6 \mathrm{~mm}, 8 \mathrm{~mm} \text { and } 10 \mathrm{~mm} \text { to investigate the sturdiest design that can withstand } \\
\text { high pressure. Static structural analysis is performed to all designs with different wall } \\
\text { thickness on SolidWorks Simulation. The maximum values of von Misses stress and } \\
\text { displacement has been presented in this paper. Validation of the results are made by } \\
\text { comparing the maximum values of von Mises stress with yield strength of the material. } \\
\text { Mixing chamber with wall thickness of } 10 \text { mm showed the best results. }\end{array}$ \\
\hline
\end{tabular}

Keywords:

Nanorefrigerant, nanoparticles,

SolidWorks, nanofluid

Copyright $\odot 2020$ PENERBIT AKADEMIA BARU - All rights reserved

\section{Introduction}

Refrigerant is a material used during heat cycle to transfer heat from one region and remove it to another. Refrigerants play an essential position in refrigeration and air conditioning systems which regularly consumes a significant proportion of energy generated, particularly in the more advanced countries for industries, commercial buildings and automotive.

Nanoparticles are a broad group of materials that include particulate substances, which have one dimension less than $100 \mathrm{~nm}$ at least [1-6]. Metal, metal oxide or carbon are some popular examples of nanoparticles. Nanorefrigerant is formed when refrigerant is mixed with small amount of nanoparticles, usually less than $4 \%$ of total volume of the mixture. Results from previous researches have shown that nanorefrigerant would achieve more than $10 \%$ better thermal conductivity compared to pure refrigerant [7-15]. The three main benefits of using refrigerants with nanoparticles are [15]: 1) Solubility between refrigerant and the lubricant can be enhanced. 2) Thermal conductivity

\footnotetext{
* Corresponding author.

E-mail address: nfazlin7@live.utm.my

https://doi.org/10.37934/araset.21.1.3240
} 
and heat transfer characteristics of the refrigerant can be improved. 3) The friction coefficient and wear rate reduces when nanoparticles are dispersed into the refrigerant. From the advantages of using nanorefrigerants, better refrigeration systems are attainable. A number of researches have been conducted to investigate the performance of nanorefrigerant.

In experimental works, the nanorefrigerant research community is divided into two groups. The first group of researchers add nanoparticles into lubricant first before disperse it into the refrigeration system. Subramani and Prakash [16] added nanoparticles into mineral oil which act as lubricant before being released in R134a refrigeration system. Bartelt et al [17] added nanoparticles into polyester lubricant ( $\mathrm{RL68H}$ ) before being released in R134a refrigeration system. The heat transfer coefficient is then measured when nanorefrigerant flowing through a horizontal tube. Henderson et al [18] added nanoparticles into polyester oil which act as lubricant before being released in R134a refrigeration system. Bi et al [19] added nanoparticles into mineral oil which act as lubricant before being released in R134a refrigeration system. The performance is then investigated by using energy consumption test and freeze capacity test. Mahbubul et al [20] added nanoparticles into POE oil which act as lubricant before being released in R134a refrigeration system.

The second group of researchers disperse nanoparticles directly into refrigerant. Park and Jung [21] added nanoparticles into long plain tube with nucleate boiling heat transfer of R134a and R132. Sun and Yang [22] performed experimental work to investigate the heat transfer and flow characteristic of nanorefrigerant. Nanoparticles was added directly into refrigerant R141b by using two-step method. The researchers chose to mix nanoparticles directly with refrigerant since R141b is a low pressure refrigerant. Jiang et al [23] also dispersed nanoparticles directly into refrigerant R113. This method is chosen since refrigerant R113 is in the liquid state at room temperature and atmospheric pressure.

From the above brief review, most researchers mix nanoparticle into lubricant first before being released and tested with refrigerant in refrigeration system. This is mostly because most refrigerant is high pressure and a gas at room temperature. Hence, it is difficult to add nanoparticles directly into refrigerant. The adding nanoparticles into lubricant is resulting in difficulties to investigate the properties of nanorefrigerant. This is because refrigerant, lubricant and nanoparticles are mixed together in the system. So, usually researchers will observe or measure the overall performance of the system to see the effectiveness of the nanoparticles. Previous studies also mostly did not investigate the sedimentation of nanorefrigerant mixture. According to some researchers, the aggregation and sedimentation of nanoparticles in the nanorefrigerant may reduce the stability of nanorefrigerant and limit the application of nanorefrigerant [24]. Therefore, it is important to check if sedimentation occurs. So for this research, a new idea of mixing nanorefrigerant is designed to overcome these limitations.

\section{Design of Mixing Chamber}

A mixing chamber was designed after background research was made. This design consists of one inlet valve and one outlet valve. The function of this mixing chamber is to mix nanoparticles with refrigerant, measure thermal conductivity of the nanorefrigerant and to observe if any sedimentation occurs. Overall size of this design is approximately $180 \mathrm{~mm}$ width, $180 \mathrm{~mm}$ length and $178 \mathrm{~mm}$ height. It is designed to be small-scale to ease the experiment process of new nanorefrigerant since it requires less proportion of materials. This design consists of seven different parts which are the cylinder body, upper cap, lower cap, small cap, stick of thermal conductivity, long screw and short screw. Each part has its own function. Figure below shows the 3D design of the mixing chamber. 


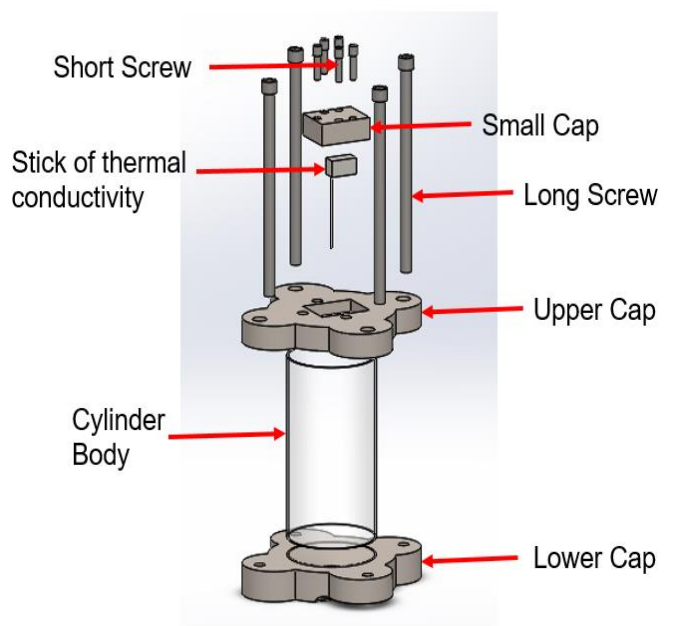

Fig. 1. Exploded view of the mixing chamber

\subsection{Static Analysis}

The mixing chamber was modelled in SolidWorks. SolidWorks Simulation is a finite element analysis (FEA) tool that enable users to make structural analysis on a structure such as displacement, stress, buckling, fatigue life and many more. Structural analysis is essential because it offers the basis for structural design and also assesses whether a particular structural design can withstand external and internal stresses and forces. Thickness of the cylindrical wall was set varies from $2 \mathrm{~mm}$ to $10 \mathrm{~mm}$. The boundary conditions for the structure are shown in Figure 2. The loading due to nanorefrigerant was modelled by pressure with the maximal value $5 \mathrm{MPa}$. A structural analysis is done to identify the most optimum wall thickness of mixing chamber body. Material chosen for the cylinder body of the chamber is acrylic. Meanwhile, aluminium is chosen as material of the upper and lower cap. The material properties of the cylinder body are: mass density $\rho=1200 \mathrm{~kg} / \mathrm{m}^{3}$ and yield point $R e=75 \mathrm{MPa}$. The material properties of the upper and lower cap are: mass density $\rho=2710 \mathrm{~kg} / \mathrm{m}^{3}$ and yield point $R e=276 \mathrm{MPa}$

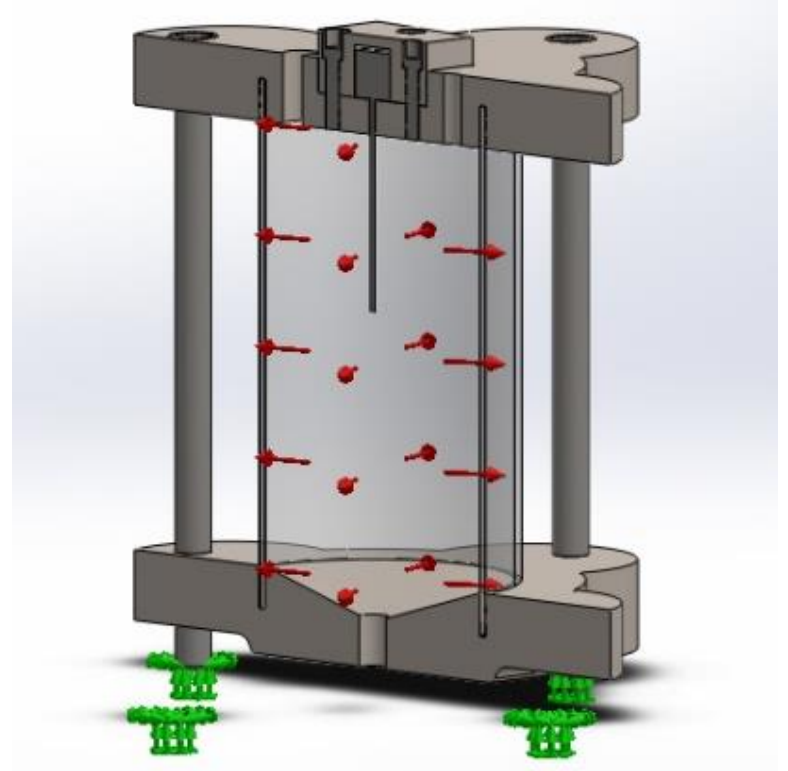

Fig. 2. Boundary conditions applied on model 
The mesh finite elements were generated as shown in figure 4. Standard mesh was chosen. The element size of $10.48 \mathrm{~mm}$ and the element size tolerance of $0.52 \mathrm{~mm}$ are established automatically based on the geometric features of the SolidWorks structure.

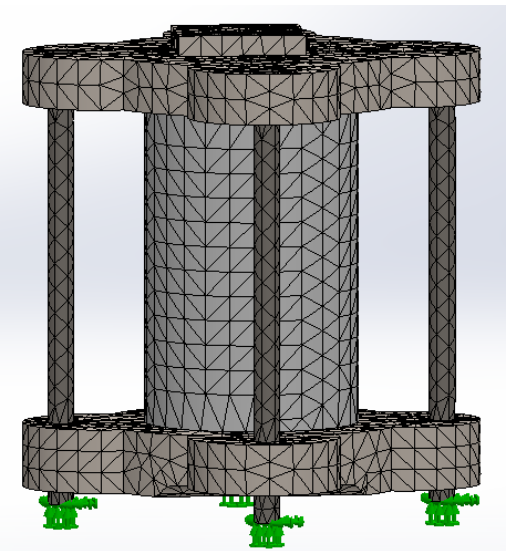

Fig. 3. Finite element mesh

\section{Results and Discussion}

The results of static analysis are given in the following figures. The results that are observed from the structural analysis are the maximum values of von Misses stress and the maximum values of displacement. Richard Elder von Misses designed an equation that uses each normal and shear stress values and make it into single value that can be used to compare with the yield strength of material [25]. The value is called "von Misses stress". By following his criteria, the part is failing if the von Misses value is greater than the yield strength. If the value is smaller, then the part is not failing since it is within the yield criteria. Material chosen for the caps is aluminium with average yield strength of $276 \mathrm{MPa}$. Acrylic was chosen as material for the cylinder and the average yield strength is $73 \mathrm{MPa}$.

Stress plot for $2 \mathrm{~mm}$ wall thickness are shown in Figure 4 . The maximum von Misses stress is 109.3 MPa and it is located at the cylinder. This value is greater than yield strength of the acrylic and hence failure will occur.

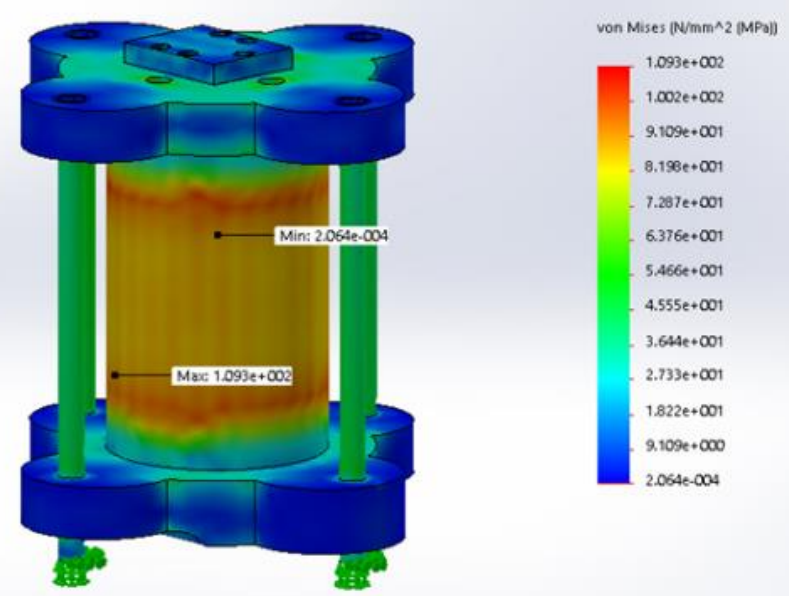

Fig. 4. Stress plot for $2 \mathrm{~mm}$ 
The maximum value of von Misses stress for mixing chamber with $4 \mathrm{~mm}$ wall thickness is 75.96 $\mathrm{MPa}$. It is located at the upper cap so that value was compared with yield strength of aluminium which is $276 \mathrm{MPa}$. The von Misses stress value is smaller than the yield point hence this mixing chamber will not experience failure. Stress plot for $4 \mathrm{~mm}$ wall thickness are shown in Figure 5 . The maximum von Misses stress for mixing chamber with wall thickness of $6 \mathrm{~mm}, 8 \mathrm{~mm}$ and $10 \mathrm{~mm}$ are 75.71 MPa, 76. 98 MPa and 78.18 MPa respectively. All of the stresses are located at the upper cap and the values are smaller than the yield strength. The value of maximum von Misses stress at mixing chamber with $10 \mathrm{~mm}$ wall is slightly higher than that value of $8 \mathrm{~mm}$ wall. However, both of these values still did not exceed the yield point hence no failure will occur.

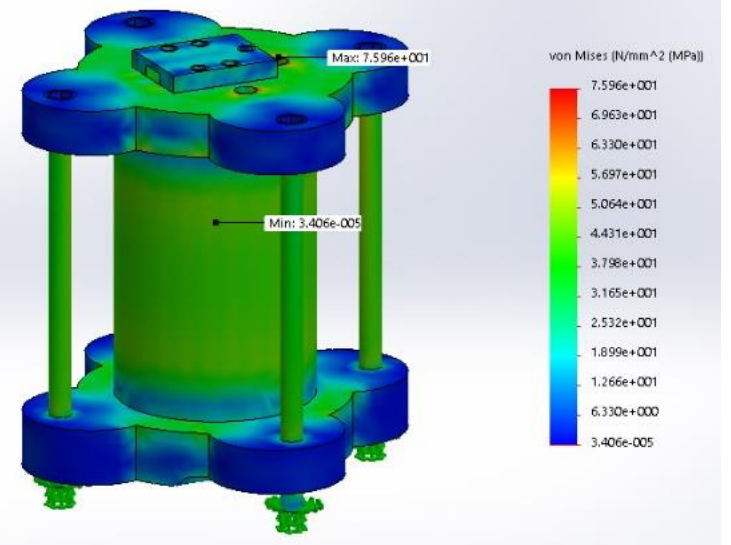

Fig. 5. Stress plot for $4 \mathrm{~mm}$

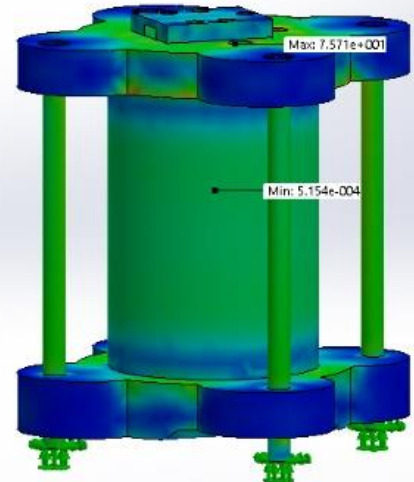

Fig. 6. Stress plot for $6 \mathrm{~mm}$

The maximum von Misses stress values acting on the mixing chamber with five different wall thickness are shown in table below. Only mixing chamber with $2 \mathrm{~mm}$ wall has maximum stress greater than yield strength of the material where the maximum stress occurs. Mixing chamber with $4 \mathrm{~mm}, 6$ $\mathrm{mm}, 8 \mathrm{~mm}$ and $10 \mathrm{~mm}$ all have values of maximum stress smaller than yield strength of the material.

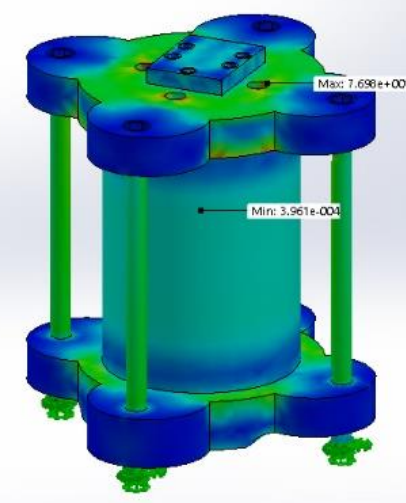

Fig. 7. Stress plot for $8 \mathrm{~mm}$

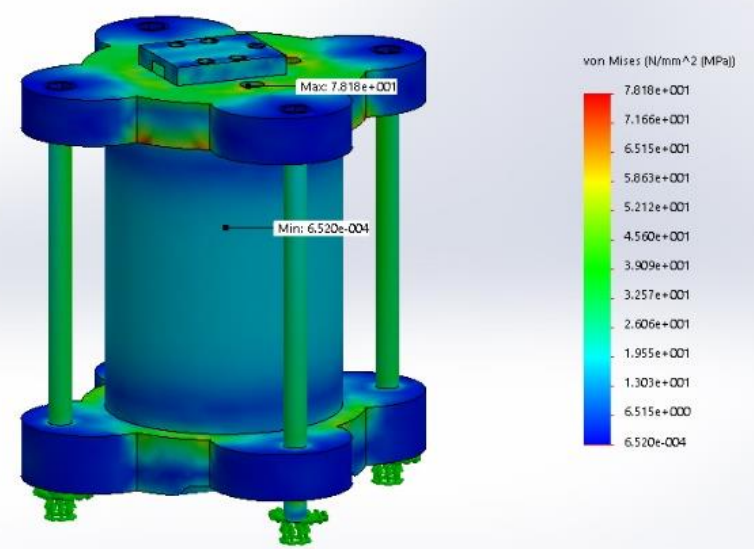

Fig. 8. Stress plot for $10 \mathrm{~mm}$ 
Table 1

Computed maximal values of von Misses stress

\begin{tabular}{|c|c|c|c|c|c|}
\hline Thickness of cylindrical wall $(\mathrm{mm})$ & 2 & 4 & 6 & 8 & 10 \\
\hline Maximum von Misses stress (MPa) & 109.30 & 75.96 & 75.71 & 76.90 & 78.1 \\
\hline
\end{tabular}

Displacement plots are also observed. The results show resultant displacement of the model. The maximum displacement value is not compared and validated with any value, unlike the von Misses stress. However, the smallest value of maximum displacement is the most favourable. Design with 2 $\mathrm{mm}$ wall thickness shows the biggest maximum displacement which is $1.445 \mathrm{~mm}$ and it is located at the cylinder. Design with wall thickness of $4 \mathrm{~mm}, 6 \mathrm{~mm}$ and $8 \mathrm{~mm}$ also show maximum displacement at the cylinder which are $0.715 \mathrm{~mm}, 0.493 \mathrm{~mm}$ and $0.387 \mathrm{~mm}$ respectively. The smallest value of maximum displacement is observed on the design with $10 \mathrm{~mm}$ of wall thickness. Displacement plot for all five different wall thickness are shown in the figures below.

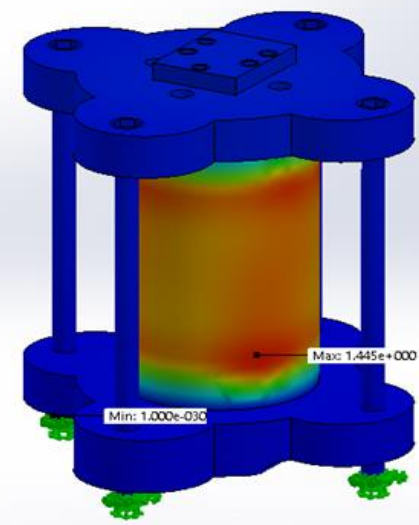

Fig. 9. Displacement plot for $2 \mathrm{~mm}$

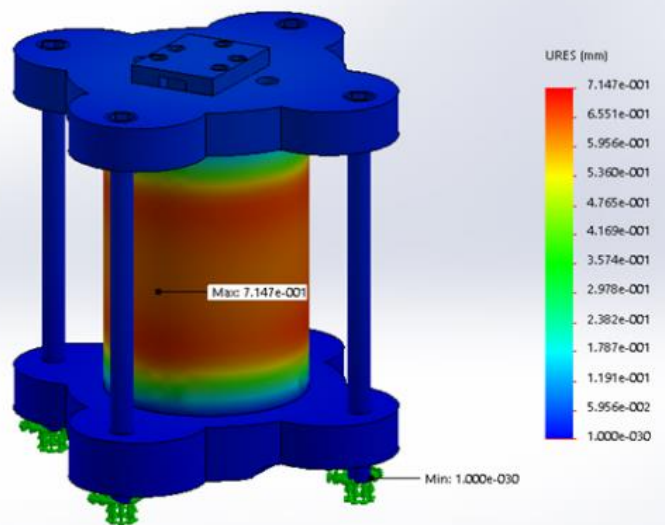

Fig. 10. Displacement plot for $4 \mathrm{~mm}$

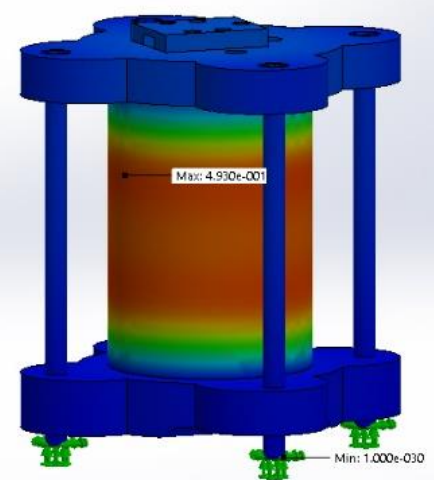

Fig. 11. Displacement plot for $6 \mathrm{~mm}$
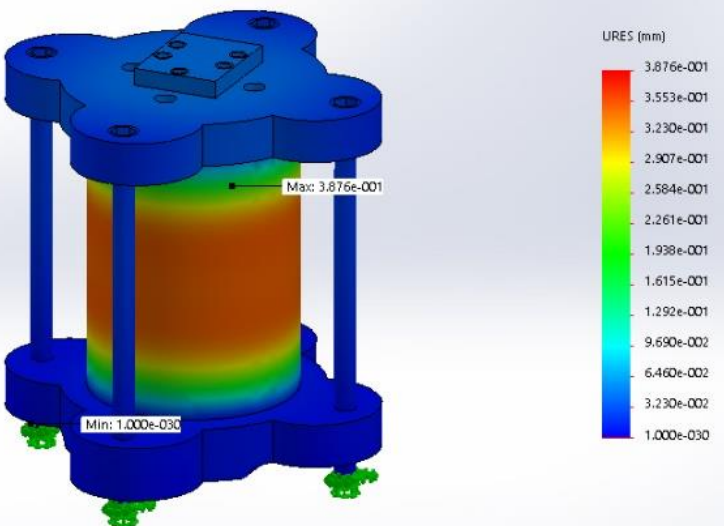

Fig. 12. Displacement plot for $8 \mathrm{~mm}$ 


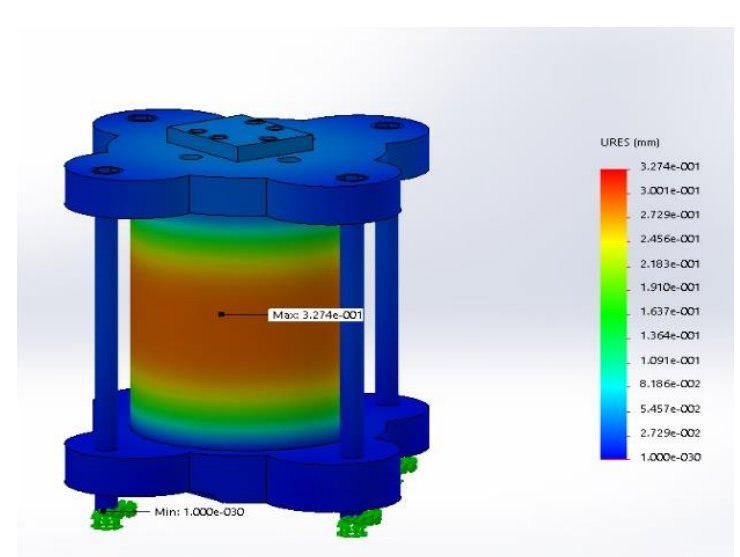

Fig. 13. Displacement plot for $10 \mathrm{~mm}$

All maximum displacement for five different thickness of mixing chamber wall is shown in table. From the static analysis, it can be seen that the thicker the wall thickness, the smaller the maximum displacement.

\section{Table 2}

Computed maximal values of displacement

\begin{tabular}{|c|c|c|c|c|c|}
\hline Thickness of Cylindrical Wall $(\mathrm{mm})$ & 2 & 4 & 6 & 8 & 10 \\
\hline Maximum Displacement $(\mathrm{mm})$ & 1.445 & 0.715 & 0.493 & 0.387 & 0.327 \\
\hline
\end{tabular}

\section{Conclusion}

Static structural analysis of the mixing chamber was performed. The mixing chamber was modelled from acrylic and aluminium as 3D body. The finite analysis was performed by SolidWorks Simulation. Five different thickness $(2 \mathrm{~mm}, 4 \mathrm{~mm}, 6 \mathrm{~mm}, 8 \mathrm{~mm}$, and $10 \mathrm{~mm}$ ) were taken into account. The von Misses stress plots and the displacement plots served for comparison of results. The maximum von Misses stress values were compared with the material yield strength to identify design failure. Mixing chamber design with wall thickness of $10 \mathrm{~mm}$ showed the lowest maximum displacement and the maximum von Misses stress does not exceed yield strength of the material. The maximum values of displacement and von Misses stress for mixing chamber with $10 \mathrm{~mm}$ wall thickness are $0.327 \mathrm{~mm}$ and $78.1 \mathrm{MPa}$ respectively.

\section{References}

[1] Safiei, W., Rahman, M. M., Hadi, M. A., Azmi, W. H., \& Arifin, M. N. “Experimental Investigation on Preparation and Stability of Al2O3 Nanofluid In Deionized Water and Ethylene Glycol." Journal of Advanced Research in Fluid Mechanics and Thermal Sciences 77, no. 2 (2020): 47-62.

[2] Jamaluddin, Nor Athira, Norfazillah Talib, and Amiril Sahab Abdul Sani. "Tribological Analyses of Modified Jatropha Oil With HBN and Graphene Nanoparticles As An Alternative Lubricant for Machining Process". Journal of Advanced Research in Fluid Mechanics and Thermal Sciences 76, no. 2 (2020):1-10. https://doi.org/10.37934/arfmts.76.2.110

[3] Mahammedi, Abdelkader, Houari Ameur, Younes Menni, and Driss Meddah Medjahed. "Numerical Study of Turbulent Flows and Convective Heat Transfer of Al2O3-Water Nanofluids In A Circular Tube". Journal of Advanced Research in Fluid Mechanics and Thermal Sciences 77, no. 2 (2020):1-12.

[4] Ahmad Nor, Yusilawati, Nurul Hafizah Khairudin, and Yumi Zuhanis Has-Yun Hashim. "Rough Hollow Mesoporous Silica Nanoparticles As Carrier for Agarwood Oil to Treat Cancer Cells". Journal of Advanced Research in Materials 
Science 54, no. 1 (2020):1-9.

[5] Adamu, Isa M., Nor Azwadi Che Sidik, and Mahmud M. Jamil. "Preparation Methods and Thermal Performance of Hybrid Nanofluids". Journal of Advanced Research in Materials Science 56, no. 1 (2020):1-10.

[6] Barom, N. H., G. Y. Ny, S. M. Noraziman, and S. T. Yeow. "Numerical Study on Turbulent-Forced Convective Heat Transfer of Ag/Heg Water Nanofluid in Pipe". Journal of Advanced Research in Materials Science 22, no 1. (2020):11-27.

[7] Zendehboudi, Alireza, Baolong Wang, and Xianting Li. "Robust model to predict the migration ratios of nanoparticles during the pool-boiling process of nanorefrigerants." International Communications in Heat and Mass Transfer 84 (2017): 75-85.

https://doi.org/10.1016/j.icheatmasstransfer.2017.03.012

[8] Saengsikhiao, Piyanut, Juntakan Taweekun, Kittinan Maliwan, Somchai Sae-ung, and Thanansak Theppaya. 2020. "Development of Environmentally - Friendly and Energy Efficient Refrigerant for Medium Temperature Refrigeration Systems". Journal of Advanced Research in Materials Science 71, no. 1 (2020):12-31. https://doi.org/10.37934/arms.71.1.1231

[9] Saengsikhiao, Piyanut, Juntakan Taweekun, Kittinan Maliwan, Somchai Sae-ung, and Thanansak Theppaya. "The Performance Simulation of The New R463A HFC/HFO/Carbon Dioxide Refrigerant With Lower GWP, As an Alternate Option for The R404A Refrigeration System". Journal of Advanced Research in Fluid Mechanics and Thermal Sciences 76, no. 1, (2020):113-23. https://doi.org/10.37934/arfmts.76.1.113123

[10] Kosmadakis, George, and Panagiotis Neofytou. "Investigating the effect of nanorefrigerants on a heat pump performance and cost-effectiveness." Thermal Science and Engineering Progress 13 (2019): 100371. https://doi.org/10.1016/i.tsep.2019.100371

[11] Zhang, Songyuan, Yunan Yu, Zheng Xu, Hui Huang, Zhennan Liu, Cong Liu, Xiaobo Long, and Zhong Ge. "Measurement and modeling of the thermal conductivity of nanorefrigerants with low volume concentrations." Thermochimica Acta (2020): 178603.

https://doi.org/10.1016/i.tca.2020.178603

[12] Sanukrishna, S. S., Maneesh Murukan, and Prakash M. Jose. "An overview of experimental studies on nanorefrigerants: Recent research, development and applications." International Journal of Refrigeration 88 (2018): 552-577.

https://doi.org/10.1016/j.ijrefrig.2018.03.013

[13] Saengsikhiao, Piyanut, Juntakan Taweekun, Kittinan Maliwan, Somchai Sae-ung, and Thanansak Theppaya. "Improving Energy Efficiency in the Supermarket by Retrofitting Low E Glass Doors for Open Refrigerated". Journal of Advanced Research in Applied Sciences and Engineering Technology 20, no. 1 (2020):11-17.

[14] Nawi, M. R. M., M. Z. A. Rehim, W. H. Azmi, and S. A. Razak. "The characterization and thermo-physical property investigations of SiO2/HFE7000 nanorefrigerants." International Journal of Refrigeration 88 (2018): 275-283. https://doi.org/10.1016/j.ijrefrig.2018.02.006

[15] Azmi, W. H., M. Z. Sharif, T. M. Yusof, Rizalman Mamat, and A. A. M. Redhwan. "Potential of nanorefrigerant and nanolubricant on energy saving in refrigeration system-A review." Renewable and Sustainable Energy Reviews 69 (2017): 415-428. https://doi.org/10.1016/i.rser.2016.11.207

[16] Subramani, N., and M. Jose Prakash. "Experimental studies on a vapour compression system using nanorefrigerants." International Journal of Engineering, Science and Technology 3, no. 9 (2011): 95-102. https://doi.org/10.4314/ijest.v3i9.8

[17] Bartelt, Kristen, Younggil Park, Liping Liu, and Anthony Jacobi. "Flow-boiling of R-134a/POE/CuO nanofluids in a horizontal tube." (2008).

[18] Henderson, Kristen, Young-Gil Park, Liping Liu, and Anthony M. Jacobi. "Flow-boiling heat transfer of R-134abased nanofluids in a horizontal tube." International Journal of Heat and Mass Transfer 53, no. 5-6 (2010): 944951.

https://doi.org/10.1016/i.ijheatmasstransfer.2009.11.026

[19] Bi, Sheng-shan, Lin Shi, and Li-li Zhang. "Application of nanoparticles in domestic refrigerators." Applied Thermal Engineering 28, no. 14-15 (2008): 1834-1843. https://doi.org/10.1016/j.applthermaleng.2007.11.018

[20] Mahbubul, I. M., R. Saidur, and M. A. Amalina. "Influence of particle concentration and temperature on thermal conductivity and viscosity of Al2O3/R141b nanorefrigerant." International Communications in Heat and Mass Transfer 43 (2013): 100-104. https://doi.org/10.1016/i.icheatmasstransfer.2013.02.004

[21] Park, Ki-Jung, and Dongsoo Jung. "Boiling heat transfer enhancement with carbon nanotubes for refrigerants 
used in building air-conditioning." Energy and Buildings 39, no. 9 (2007): 1061-1064. https://doi.org/10.1016/j.enbuild.2006.12.001

[22] Yang, Di, Bin Sun, Hongwei Li, and Xiaochao Fan. "Experimental study on the heat transfer and flow characteristics of nanorefrigerants inside a corrugated tube." International Journal of Refrigeration 56 (2015): 213-223. https://doi.org/10.1016/i.ijrefrig.2015.04.011

[23] Jiang, Weiting, Guoliang Ding, and Hao Peng. "Measurement and model on thermal conductivities of carbon nanotube nanorefrigerants." International Journal of Thermal Sciences 48, no. 6 (2009): 1108-1115. https://doi.org/10.1016/i.ijthermalsci.2008.11.012

[24] Alawi, Omer A., and Nor Azwadi Che Sidik. "Mathematical correlations on factors affecting the thermal conductivity and dynamic viscosity of nanorefrigerants." International Communications in Heat and Mass Transfer 58 (2014): 125-131. https://doi.org/10.1016/i.icheatmasstransfer.2014.08.033

[25] Von Mises, Richard. Mathematical theory of probability and statistics. Academic Press, 2014. 